\title{
Analyzing Jump Risk and its Contagious Effect of Stock Asset in Jump-GARCH Model with Threshold and Variable Intensity
}

\author{
Huang $\operatorname{Ran}^{1}, K_{e}$ Qiao $^{1}$, Tang Qiming ${ }^{2}$ \\ ${ }^{1}$ School of Economics and Industrial and Commercial Management Central China Normal University, P.R. China, \\ ${ }^{2}$ School of Economics HuaZhong University of Science and Technology, P.R. China
}

\begin{abstract}
- we build the threshold-based state-dependent autoregressive jump intensity-GARCH model to study smooth fluctuations and jump changes of individual stocks listed in China. It makes the jump intensity not only driven by idiosyncratic factors, but impacted by external state variables. Comparing with the existing models, it boasts better goodness of fit and explanatory ability. It not only can more clearly describe the time variation, clustering and threshold-based state-dependence of jump changes as well as capture the asymmetry and clustering in normal volatility, but also can better illustrate the risk contagion between cross-shareholding companies.

Key words: stock asset; jump risk; threshold; variable intensity; contagion
\end{abstract}

\section{I . Introduction}

Since 1990s, China have been impacted greatly by the external and internal unexpected events, such as US financial crisis, Europeans debt crisis, snow disasters and earthquakes, which further intensify incompleteness and instability of their financial markets. Because of the increasingly obvious double features of normal fluctuation and jump change in financial asset return, it becomes more and more important to research and monitor the jump risk.

Actually, many studies had already paid attention to the jump changes in return of financial assets in 1970s. However, the shortcoming of these early jump-diffusion models is they assume the unchangeable jump intensity and frequency of jump process. Thus, the researches after them focused on relaxing the assumption of constant jump intensity, such as Bekaert and Gray(1998), and Neely(1999). They build external variables based intensity models, which make the jump intensity driven by some macro economic variables. Das(2002) use dummy variables to denote each day of the week to further analyze their effects on the intensity of jumps.

However, these models still can not explain the phenomenon of clustering in jump changes. Therefore, the recent researches have turned to emphasize time-varying and cross-period dependence of jump intensity. Johannes et al. (1999) builds a state-dependent model (SDJ), which takes the previous jump of the asset and the previous volatility of market index as the explanatory variables to explain the probability that jump occurs currently. Chan and Maheu(2002) proposes the ARJI-GARCH model to internalize the change of intensity, supposing the jump intensity follows a autoregression process. But this model also has limitation because it defines the jump intensity as a process driven wholly and only by internal idiosyncratic factors. Maheu and Mccurdy(2004) further discusses the effects of good, bad, normal and unusual news on the individual stock. Daal et al. (2007) takes previous volatility of market index into model as state-variable to study its effect on the present jump change in the rate of return of market index.

Overall, the studies above relatively better capture the jump feature of the stock assets to some extent, however, most of them only focus on the jump in macro financial market. A few of them, although paying attention to the micro financial assets, only analyze the internal mechanism of jump changes in disregard of the effect of external state variables.

While no one model captures these best, we develop the threshold based state-dependent, autoregressive jump intensity model (TSD-ARJI-GARCH) to describe both normal fluctuations and jump changes in the return of stocks and study the contagious effects of large fluctuations between cross-shareholding companies. It extends the existing models and improves their disadvantages of only considering the effect of external factors on jumps in individual stocks or only considering internal mechanisms of these jumps. It makes the jump intensity not only driven by idiosyncratic factors, but impacted by systematic or relevant state variables, and uses the threshold to measure the asymmetric effects of external factors.

\section{II . Theoretical model and parameters estimation}

The changes in price of stock are driven by unpredictable information flow, and the potential information flow includes "normal" and "abnormal" news, each of which has totally different effect on the rate of return. The diffusion of normal news causes the smooth fluctuation, which can be captured by diffusion process (Merton, 1976). The impact of abnormal news induces the unexpected large change (called "jump" in Maheu and Mccurdy (2004)), which can be described by nonhomogeneous Poisson process (Tang and Huang, 2010).

Therefore, suppose the price of stock $S_{t}$ satisfy the stochastic-differential equation below on $(t-1, t)$ :

$$
\frac{d S_{t}}{S_{t}}=\left(\mu-\lambda_{t} \cdot v\right) d t+\sigma_{t} d B_{t}+\left(J_{t}-1\right) d N_{t},
$$

where $\mu$, a constant, denotes the expected rate of return; $B_{t}$ is a Brown motion under the real probability measure; $\sigma_{t}$ is 
the conditional volatility of normal diffusion fluctuation. We suppose that $\sigma_{t}$ varies with the time and follows GARCH model (3), but takes constant value over $(t-1, t)$.

$N_{t}$ is a non-homogeneous Poisson process with the parameter $\lambda_{t} \cdot \lambda_{t}$, denoting the conditional jump intensity over $(t-1, t)$, is the ex-ante forecast on the number of jumps on $(t-1, t)$ based on $\Omega_{t-1}\left(\Omega_{t-1}\right.$ is the set of all information at and before time $t-1)$, i.e., $\lambda_{t}=E\left(N_{t} \mid \Omega_{t-1}\right)$. We suppose that $\lambda_{t}$ varies with the time and follows the TSD-ARJI model (4), but takes constant value on $(t-1, t)$.

$J_{t}(>0)$, representing the jump amplitude, follows the lognormal distribution with mean value $\theta$ and variance $\delta^{2}$, i.e. $\ln J_{t} \sim N\left(\theta, \delta^{2}\right)$. Both $\theta$ and $\delta^{2}$ are constants. Define $v$ as $v:=E\left(J_{t}-1\right)=\exp \left(\theta+\frac{\delta^{2}}{2}\right)-1$.

Assume $B_{t}, N_{t}$ and $J_{t}$ are independent with each other, so according to the theorem of stochastic-exponential (Klebaner, 2005), the Eq.(1) has the only closed form solution as follows:

$r_{t}=\ln \frac{S_{t}}{S_{t-1}}=\left(\mu-\frac{1}{2} \sigma_{t}^{2}-\lambda_{t} \cdot v\right)+\sigma_{t}\left(B_{t}-B_{t-1}\right)+\sum_{i=1}^{N_{t}} \ln J_{t}^{i}$

where $J_{t}^{i}(>0)$ denotes the jump amplitude of the ith jump on $(t-1, t) . J_{t}^{i}(>0)$ and $J_{t}$ are i.i.d.. From the solution (2), we can clearly see that the rate of return of stock asset is affected by both normal diffusion fluctuation risk $\sigma_{t}\left(B_{t}-B_{t-1}\right)$ and abnormal jump risk $\sum_{i=1}^{N_{t}} \ln J_{t}^{i}$.

\section{A. GARCH model for conditional volatility of normal diffusion fluctuation}

Lots of empirical researches find that the conditional volatility of normal diffusion fluctuation $\sigma_{t}^{2}$ has three important features: 1) big $\sigma_{t}^{2} \mathrm{~s}$ or small $\sigma_{t}^{2} \mathrm{~s}$ tend to occur in clustering manner, which means $\sigma_{t}^{2}$ in the previous period has effect on the current one; 2) $\varepsilon_{t-1}^{2}$, denoting the residual that the rate of return deviates from the conditional mean, in the previous period also has effect on the current $\sigma_{t}^{2}$, which is called GARCH-effect of conditional volatility; 3 ) the effect of $\varepsilon_{t-1}^{2}$ on $\sigma_{t}^{2}$ is asymmetric based on bad or good news.

Thus, we suppose $\sigma_{t}^{2}$ follows the GARCH $(1,1)$ below to capture all three features above.

$$
\sigma_{t}^{2}=\omega_{0}+\left(\omega_{1}+I\left(\varepsilon_{t-1}\right) \cdot \omega_{2}\right) \cdot \varepsilon_{t-1}^{2}+\omega_{3} \cdot \sigma_{t-1}^{2}
$$

where $t$ is an integer and $t \geq 2, \varepsilon_{t-1}=r_{t-1}-E\left(r_{t-1} \mid \Omega_{t-2}\right)$ denotes the residual that the rate of return deviates from the conditional mean; $I\left(\varepsilon_{t-1}\right)=\left\{\begin{array}{ll}1, & \text { if } \varepsilon_{t-1}<0 \\ 0, & \text { if } \varepsilon_{t-1} \geq 0\end{array}\right.$, is a dummy variable. So if the stock asset experienced the good news in previous period $\left(\varepsilon_{t-1} \geq 0\right)$, the effect of $\varepsilon_{t-1}$ on current $\sigma_{t}^{2}$ is $\omega_{1} \cdot \varepsilon_{t-1}^{2}$, but if stock asset suffered the bad news in previous period $\left(\varepsilon_{t-1}<0\right)$, the effect of $\varepsilon_{t-1}$ on current $\sigma_{t}^{2}$ is $\left(\omega_{1}+\omega_{2}\right) \cdot \varepsilon_{t-1}^{2}$. $\omega_{2} \cdot \varepsilon_{t-1}^{2}$ measures the additional effect of bad news.

When estimating the parameters in above model, we must suppose $\omega_{0} \geq 0, \omega_{1} \geq 0, \omega_{2} \geq 0$ and $\omega_{3} \geq 0$ to ensure $\sigma_{t}^{2} \geq 0$.

\section{B . Threshold Based State-Dependent, Autoregressive Jump Intensity Model}

Based on the existing researches, $\lambda_{t}$ boasts the features of variation, clustering and cross-periods dependence. Moreover, we find it is also affected by the systematic or relevant fluctuation. In order to comprehensively capture these features, this paper extends the existing model with changeable intensity and builds the TSD-ARJI model as

$$
\lambda_{t}=\lambda_{0}+\beta_{1} \cdot \lambda_{t-1}+\beta_{2} \cdot \eta_{t-1}+\left(I\left(E X F_{t-1}\right) \cdot \beta_{3}\right) \cdot E X F_{t-1}
$$

where $t$ is an integer and $t \geq 2 ; \lambda_{0}$, a constant, denotes the unchangeable part in conditional jump intensity.

$$
\lambda_{t-1}=E\left(N_{t-1} \mid \Omega_{t-2}\right) \quad \text { represents the one-period lag }
$$
conditional intensity, which is the ex-ante forecast on the jump at time $t-1$ based on the set of information at $t-2$.

$$
\eta_{t-1}=\kappa_{t-1}-\lambda_{t-1}=E\left(N_{t-1} \mid \Omega_{t-1}\right)-E\left(N_{t-1} \mid \Omega_{t-2}\right) \text { is the term of error }
$$
calibration. $\kappa_{t-1}=E\left(N_{t-1} \mid \Omega_{t-1}\right)$ is the ex-post inference on the jump over $(t-2, t-1)$ based on the set of information at time $t-1$.

According to the definition of mean of random variable, $\kappa_{t-1}=E\left(N_{t-1} \mid \Omega_{t-1}\right)=\sum_{k=0}^{\infty} k \cdot P\left(N_{t-1}=k \mid \Omega_{t-1}\right)$, and $P\left(N_{t-1}=k \mid \Omega_{t-1}\right)$, denoted by the formula below, is the ex-post probability that $\mathrm{k}$ jumps occur in $(t-2, t-1)$ based on the set of information $\Omega_{t-1}$.

$P\left(N_{t-1}=k \mid \Omega_{t-1}\right)=\frac{f\left(r_{t-1} \mid N_{t-1}=k, \Omega_{t-2}\right) P\left(N_{t-1}=k \mid \Omega_{t-2}\right)}{f\left(r_{t-1} \mid \Omega_{t-2}\right)}, \quad k=0,1,2 \cdots$

where $f(\square \mid \square)$ denotes the conditional probability density function. $P\left(N_{t-1}=k \mid \Omega_{t-2}\right)=\frac{e^{-\lambda_{t-1}}\left(\lambda_{t-1}\right)^{k}}{k !}$ represents the ex-ante probability that $\mathrm{k}$ jumps occur on $(t-2, t-1)$ based on the set of information $\Omega_{t-2}$.

In Eq. (4), $E X F_{t-1}$ denotes the state variable at time $t-1$. It is added into model to capture the change of conditional intensity $\lambda_{t}$ when the relevant external state variables vary with the time.

In addition, in empirical research, we find only when the change of external state variable (such as market index or relevant stock) is larger than some particular threshold, they 
have obvious effect on the jump behavior of individual stock asset, that is, only relatively larger change of external state variable can induce an obvious response in intensity $\lambda_{t}$. Therefore, we use a dummy variable $I\left(E X F_{t-1}\right)$ to classify $E X F_{t-1}$ into "big impact" and "small impact". If $E X F_{t-1}>K$ where $K(\geq 0)$ represents the threshold, i.e. a big impact, we have $I\left(E X F_{t-1}\right)=1$. If $E X F_{t-1} \leq K$, i.e. a small impact, we have $I\left(E X F_{t-1}\right)=0$.

When estimating the parameters in above model, we also must suppose $\lambda_{0} \geq 0, \beta_{1} \geq 0, \beta_{2} \geq 0$ and $\beta_{3} \geq 0$ to ensure that $\lambda_{t} \geq 0$.

\section{Estimation of Parameters}

We use the method of maximum likelihood estimation to estimate the parameters in TSD-ARJI-GARCH model (2), (3) and (4). Suppose the conditional PDF of the rate of return, $r_{t}$, is given by $f\left(r_{t} \mid \Omega_{t-1}\right)$, in which $\Omega_{t-1}$ is the set of information known at and before time $t-1$. Thus the log-likelihood function of the model is given by:

$$
\begin{aligned}
M & =\log F\left(r_{i}, r_{2} \cdot r_{T}\right)=\log \left(f\left(r_{i}\right) \cdot \prod_{t=2}^{T} f\left(r_{i} \mid \Omega_{i-1}\right)\right) \\
& =\log \left(f\left(r_{i}\right)\right)+\sum_{i=2}^{T} \log \left(f\left(r_{i} \mid \Omega_{-1}\right)\right)(6)
\end{aligned}
$$

Using the total probability formula, we have

$$
f\left(r_{t} \mid \Omega_{t-1}\right)=\sum_{k=0}^{\infty} f\left(r_{t} \mid N_{t}=k, \Omega_{t-1}\right) \cdot P\left(N_{t}=k \mid \Omega_{t-1}\right)
$$

where $f\left(r_{t} \mid N_{t}=k, \Omega_{t-1}\right)$ is the PDF of $r_{t}$ conditional on $\Omega_{t-1}$ and $\mathrm{k}$ jumps occurring at time $t$, while $P\left(N_{t}=k \mid \Omega_{t-1}\right)=\frac{e^{-\lambda_{t}}\left(\lambda_{t}\right)^{k}}{k !}$ is ex-ante probability that $\mathrm{k}$ jumps occur on $t$ based on $\Omega_{t-1}$.

From (2), we know $\left(\mu-\frac{1}{2} \sigma_{t}^{2}-\lambda_{t} \cdot v\right)$ is a constant over $(t-1, t),\left(B_{t}-B_{t-1}\right) \sim N(0,1)$, and $\ln J_{t}^{i}$ and $\ln J_{t}$ are i.i.d. As we known, the linear combination of normally distributed variables still follows the normal distribution, so $f\left(r_{t} \mid N_{t}=k, \Omega_{t-1}\right)$ is a normal PDF provided by

$$
\begin{aligned}
f\left(r_{t} \mid N_{t}=k, \Omega_{-1}\right)= & \frac{1}{\sqrt{2 \pi\left(\sigma_{t}^{2}+k \delta^{2}\right)}} \\
& \cdot \exp \left[-\frac{\left(r_{t}-\left(\mu-\frac{1}{2} \sigma_{t}^{2}-\lambda_{t} \cdot v+k \theta\right)\right)^{2}}{2\left(\sigma_{t}^{2}+k \delta^{2}\right)}\right]
\end{aligned}
$$

Combining (7) with (8), we have

$$
f\left(r_{t} \mid \Omega_{4-1}\right)=\sum_{k=0}^{\infty} \frac{e^{-\lambda_{t}}\left(\lambda_{t}\right)^{k}}{k !} \cdot \frac{1}{\sqrt{2 \pi\left(\sigma_{t}^{2}+k \delta^{2}\right)}}
$$

$$
\cdot \exp \left[-\frac{\left(r_{t}-\left(\mu-\frac{1}{2} \sigma_{t}^{2}-\lambda_{t} \cdot v+k \theta\right)\right)^{2}}{2\left(\sigma_{t}^{2}+k \delta^{2}\right)}\right]
$$

Now taking (9) into (6), we can get the expression of $\log$ likelihood function.

When estimating parameters, we neglect the probability that $N_{t}>10$ in all calculations linked with the unlimited sum, because the probability that $N_{t}>10$ is small enough to be ignored. In addition, the initial value is set as $\lambda_{1}=\lambda_{0}, \sigma_{1}^{2}=\omega_{0}$ when we use the iteration procedure to estimate the model.

\section{EMPIRICAL RESEARCHES}

\section{A. Data}

All stocks we choose must meet the following conditions: (a) the sample company must have already completed the shareholding system reform and issues stocks only in China's A Share Market; (b) the ST company was imposed special treatment only in 2009 and has at least 6 years daily data before 2009; (c) the non-ST company must have historical daily exchange data since 2003 and is not specially treated in sample period. (d) in order to analyze the effect of shareholding company on share-held company, the share holding pattern must be single-directional holding and the ratio of holding is larger than or equal to $15 \%$ in sample period; (e) only collect the obtainable daily closing price and neglect the short-time trade suspension. But if the suspension time is too long to induce the abnormal jump, we will delete the daily rate of return on the very day of resuming trade to eliminate this effect.

In empirical research, we randomly choose 22 qualified companies, including 6 ST companies, 6 non-ST companies in the same sectors and 10 cross-shareholding companies (5 shareholding companies and 5 share-held companies respectively). Because the dividends paid by the company also cause the jump in stock price, we use recovered price data to eliminate this kind of jump.

\section{$B$. Estimation results and models comparison}

By using the sample data, we estimate three models respectively, including ARJI (Autoregressive Jump Intensity Model, and here $\beta_{3}=0, \omega_{1}=\omega_{2}=\omega_{3}=0$ ), ARJI-GARCH Model (here $\beta_{3}=0$ ) and TSD-ARJI-GARCH Model, and evaluate their goodness of fit according to LR Test and AIC. The estimation results are shown in Table 1.

When estimating TSD-ARJI-GARCH Model, we choose the volatility of stock market (represented by the absolute value of the return rate of China's A Share Market Index) as state variable to capture the systematic effect of the market on the individual jump, and choose the volatility of cross-holding companies (represented by the absolute value of their rates of return) as state variable to capture the contagious effect between the closely linked companies. The Maximum Likelihood (ML) estimated values and LR Testing ( $\left.\mathrm{H} 0: \beta_{3}=0\right)$ results for some companies are listed in Table I. 
TABLE I ML Estimated Value, AIC and LR Testing Results

\begin{tabular}{|c|c|c|c|c|c|c|}
\hline Co. & ARJI & \begin{tabular}{|c|} 
ARJI- \\
GARCH \\
\end{tabular} & \multicolumn{2}{|c|}{ TSD-ARJI-ARCH } & \multicolumn{2}{|c|}{ LR Testing } \\
\hline $\begin{array}{c}\text { Jinjian } \\
\text { miye }\end{array}$ & $\begin{array}{l}2926.9 \\
(-4.15)\end{array}$ & $\begin{array}{l}2936.1 \\
(-4.15)\end{array}$ & \multicolumn{2}{|c|}{$\begin{array}{c}2942.1 \\
(-4.167) \\
\end{array}$} & \multicolumn{2}{|c|}{$\begin{array}{c}12.0 \\
p=0.000\end{array}$} \\
\hline $\begin{array}{c}\text { ST } \\
\text { GanHua }\end{array}$ & $\begin{array}{l}2425.6 \\
(-3.41)\end{array}$ & $\begin{array}{l}2429.1 \\
(-3.41)\end{array}$ & \multicolumn{2}{|c|}{$\begin{array}{c}2430.7 \\
(-3.415)\end{array}$} & \multicolumn{2}{|c|}{$\begin{array}{c}3.2 \\
\mathrm{p}=0.074\end{array}$} \\
\hline $\begin{array}{l}\text { HuXin } \\
\text { ShuiNi }\end{array}$ & $\begin{array}{l}3050.5 \\
(-4.35)\end{array}$ & $\begin{array}{l}3052.5 \\
(-4.34)\end{array}$ & \multicolumn{2}{|c|}{$\begin{array}{r}3063.5 \\
(-4.368) \\
\end{array}$} & \multicolumn{2}{|c|}{$\begin{array}{c}22.0 \\
\mathrm{p}=0.000\end{array}$} \\
\hline ST JinDing & $\begin{array}{l}2572.7 \\
(-3.65)\end{array}$ & $\begin{array}{l}2581.1 \\
(-3.66)\end{array}$ & \multicolumn{2}{|c|}{$\begin{array}{c}2584.2 \\
(-3.668)\end{array}$} & \multicolumn{2}{|c|}{$\begin{array}{c}6.2 \\
\mathrm{p}=0.013\end{array}$} \\
\hline $\begin{array}{c}\text { HengRuiYi } \\
\text { Yao }\end{array}$ & $\begin{array}{l}3346.4 \\
(-4.71)\end{array}$ & $\begin{array}{l}3344.3 \\
(-4.70)\end{array}$ & \multicolumn{2}{|c|}{$\begin{array}{c}3349.5 \\
(-4.709)\end{array}$} & \multicolumn{2}{|c|}{$\begin{array}{c}10.4 \\
\mathrm{p}=0.001\end{array}$} \\
\hline $\begin{array}{c}\text { ST } \\
\text { TianFang }\end{array}$ & $\begin{array}{l}3064.1 \\
(-4.38)\end{array}$ & $\begin{array}{l}3067.7 \\
(-4.39)\end{array}$ & \multicolumn{2}{|c|}{$\begin{array}{c}3071.8 \\
(-4.395)\end{array}$} & \multicolumn{2}{|c|}{$\begin{array}{c}8.2 \\
\mathrm{p}=0.004\end{array}$} \\
\hline $\begin{array}{l}\text { ZongYi } \\
\text { GuFen }\end{array}$ & $\begin{array}{l}2780.5 \\
(-3.89)\end{array}$ & $\begin{array}{l}2780.6 \\
(-3.89)\end{array}$ & \multicolumn{2}{|c|}{$\begin{array}{c}2785.6 \\
(-3.897)\end{array}$} & \multicolumn{2}{|c|}{$\begin{array}{c}10.0 \\
\mathrm{p}=0.002\end{array}$} \\
\hline $\begin{array}{c}\text { ST } \\
\text { PianZhuan }\end{array}$ & $\begin{array}{l}2141.9 \\
(-3.15)\end{array}$ & $\begin{array}{l}2147.3 \\
(-3.15)\end{array}$ & \multicolumn{2}{|c|}{$\begin{array}{c}2148.5 \\
(-3.153)\end{array}$} & \multicolumn{2}{|c|}{$\begin{array}{c}2.4 \\
\mathrm{p}=0.121\end{array}$} \\
\hline $\begin{array}{l}\text { DongFang } \\
\text { ReDian }\end{array}$ & $\begin{array}{l}3085.3 \\
(-4.39)\end{array}$ & $\begin{array}{l}3091.2 \\
(-4.39)\end{array}$ & \multicolumn{2}{|c|}{$\begin{array}{l}3094.1 \\
(-4.40)\end{array}$} & \multicolumn{2}{|c|}{$\begin{array}{c}5.8 \\
\mathrm{p}=0.016\end{array}$} \\
\hline $\begin{array}{c}\text { ST } \\
\text { NengShan }\end{array}$ & $\begin{array}{l}2754.2 \\
(-3.92) \\
\end{array}$ & $\begin{array}{l}2764.4 \\
(-3.93) \\
\end{array}$ & \multicolumn{2}{|c|}{$\begin{array}{l}2770.5 \\
(-3.95)\end{array}$} & \multicolumn{2}{|c|}{$\begin{array}{c}12.2 \\
\mathrm{p}=0.000\end{array}$} \\
\hline $\begin{array}{c}\text { LangChao } \\
\text { XinXi }\end{array}$ & $\begin{array}{l}3001.9 \\
(-4.21)\end{array}$ & $\begin{array}{l}3007.1 \\
(-4.21)\end{array}$ & \multicolumn{2}{|c|}{$\begin{array}{l}3016.1 \\
(-4.23)\end{array}$} & \multicolumn{2}{|c|}{$\begin{array}{c}18.0 \\
\mathrm{p}=0.000\end{array}$} \\
\hline ST BoDao & $\begin{array}{l}3042.9 \\
(-4.30)\end{array}$ & $\begin{array}{l}3044.2 \\
(-4.30)\end{array}$ & \multicolumn{2}{|c|}{$\begin{array}{l}3046.4 \\
(-4.31)\end{array}$} & \multicolumn{2}{|c|}{$\begin{array}{c}4.4 \\
\mathrm{p}=0.036\end{array}$} \\
\hline Co. & ARJI & \begin{tabular}{|c|} 
ARJI- \\
GARCH
\end{tabular} & $\begin{array}{c}\begin{array}{c}\text { Systematic } \\
\text { Effect }\end{array} \\
\end{array}$ & $\begin{array}{c}\text { LR } \\
\text { Testing }\end{array}$ & \begin{tabular}{|c|} 
Contagiou \\
s Effect \\
\end{tabular} & $\begin{array}{c}\text { LR } \\
\text { Testing }\end{array}$ \\
\hline $\begin{array}{c}\text { BaoXin } \\
\text { RuanJian } \\
\end{array}$ & $\begin{array}{l}3020.4 \\
(-4.39) \\
\end{array}$ & $\begin{array}{l}3037.5 \\
(-4.41) \\
\end{array}$ & $\begin{array}{l}3046.1 \\
(-4.42) \\
\end{array}$ & $\begin{array}{c}17.2 \\
\mathrm{p}=0.00\end{array}$ & $\begin{array}{c}3047.5 \\
(-4.423) \\
\end{array}$ & $\begin{array}{c}20.0 \\
\mathrm{p}=0.00\end{array}$ \\
\hline $\begin{array}{c}\text { BaoGangG } \\
\text { uFen }\end{array}$ & $\begin{array}{l}3509.0 \\
(-5.10)\end{array}$ & $\begin{array}{l}3516.2 \\
(-5.10)\end{array}$ & $\begin{array}{l}3522.1 \\
(-5.13)\end{array}$ & $\begin{array}{c}11.8 \\
\mathrm{p}=0.00\end{array}$ & $\begin{array}{c}3517.1 \\
(-5.107)\end{array}$ & $\begin{array}{c}1.8 \\
\mathrm{p}=0.18\end{array}$ \\
\hline $\begin{array}{l}\text { NingBo } \\
\text { LianHe }\end{array}$ & $\begin{array}{l}3245.9 \\
(-4.68)\end{array}$ & $\begin{array}{l}3260.2 \\
(-4.69) \\
\end{array}$ & $\begin{array}{l}3261.1 \\
(-4.70)\end{array}$ & $\begin{array}{c}1.8 \\
\mathrm{p}=0.18\end{array}$ & $\begin{array}{l}3264.5 \\
(-4.702) \\
\end{array}$ & $\begin{array}{c}8.6 \\
p=0.00\end{array}$ \\
\hline $\begin{array}{l}\text { WuKuang } \\
\text { FaZhan } \\
\end{array}$ & $\begin{array}{l}2792.6 \\
(-4.02) \\
\end{array}$ & $\begin{array}{l}2796.8 \\
(-4.02) \\
\end{array}$ & $\begin{array}{l}2798.1 \\
(-4.03) \\
\end{array}$ & $\begin{array}{c}2.6 \\
\mathrm{p}=0.10\end{array}$ & $\begin{array}{c}2794.4 \\
(-4.022) \\
\end{array}$ & $\begin{array}{c}4.8 \\
\mathrm{p}=1.00\end{array}$ \\
\hline $\begin{array}{l}\text { TongJun } \\
\text { Ge }\end{array}$ & $\begin{array}{l}2609.9 \\
(-3.83)\end{array}$ & $\begin{array}{l}2617.9 \\
(-3.84) \\
\end{array}$ & $\begin{array}{l}2621.8 \\
(-3.85)\end{array}$ & $\begin{array}{c}7.8 \\
\mathrm{p}=0.00\end{array}$ & $\begin{array}{c}2622.8 \\
(-3.849) \\
\end{array}$ & $\begin{array}{c}9.8 \\
\mathrm{p}=0.00\end{array}$ \\
\hline $\begin{array}{l}\text { Taijiji } \\
\text { Tuan }\end{array}$ & $\begin{array}{l}2464.9 \\
(-3.61) \\
\end{array}$ & $\begin{array}{l}2477.8 \\
(-3.63) \\
\end{array}$ & $\begin{array}{l}2482.1 \\
(-3.64) \\
\end{array}$ & $\begin{array}{c}9.6 \\
\mathrm{p}=0.00\end{array}$ & $\begin{array}{r}2482.6 \\
(-3.642) \\
\end{array}$ & $\begin{array}{c}8.2 \\
p=0.00\end{array}$ \\
\hline $\begin{array}{l}\text { XinJiang } \\
\text { ZhongH } \\
\end{array}$ & $\begin{array}{l}2771.8 \\
(-4.21) \\
\end{array}$ & $\begin{array}{l}2778.4 \\
(-4.22) \\
\end{array}$ & $\begin{array}{l}2782.1 \\
(-4.23) \\
\end{array}$ & $\begin{array}{c}7.4 \\
p=0.00\end{array}$ & $\begin{array}{r}2782.3 \\
(-4.226) \\
\end{array}$ & $\begin{array}{c}7.8 \\
p=0.00\end{array}$ \\
\hline $\begin{array}{c}\text { TeBian } \\
\text { DianGong }\end{array}$ & $\begin{array}{l}2803.1 \\
(-4.26)\end{array}$ & $\begin{array}{l}2813.5 \\
(-4.27) \\
\end{array}$ & $\begin{array}{l}2813.7 \\
(-4.27)\end{array}$ & $\begin{array}{c}0.4 \\
\mathrm{p}=0.52\end{array}$ & $\begin{array}{c}2812.4 \\
(-4.270)\end{array}$ & $\begin{array}{c}-2.2 \\
\mathrm{p}=1.00\end{array}$ \\
\hline $\begin{array}{c}\text { TaiHao } \\
\text { KeJi }\end{array}$ & $\begin{array}{l}2889.1 \\
(-4.22)\end{array}$ & $\begin{array}{l}2891.4 \\
(-4.22)\end{array}$ & $\begin{array}{l}2893.5 \\
(-4.23)\end{array}$ & $\begin{array}{c}4.2 \\
p=0.04\end{array}$ & $\begin{array}{l}2893.8 \\
(-4.227)\end{array}$ & $\begin{array}{c}4.8 \\
\mathrm{p}=0.02\end{array}$ \\
\hline $\begin{array}{l}\text { TongFang } \\
\text { GuFen }\end{array}$ & $\begin{array}{l}2874.5 \\
(-4.20)\end{array}$ & $\begin{array}{l}2884.1 \\
(-4.21)\end{array}$ & $\begin{array}{l}2888.5 \\
(-4.22)\end{array}$ & $\begin{array}{c}8.8 \\
\mathrm{p}=0.00\end{array}$ & $\begin{array}{c}2886.2 \\
(-4.216)\end{array}$ & $\begin{array}{c}4.2 \\
p=0.04\end{array}$ \\
\hline
\end{tabular}

Note: Value of AIC is shown in parenthesis; $\mathbf{p}$ is the probability of committing a type I error if rejecting the hypothesis $\beta_{3}=0$

According to Table I, we get following results:

(1) Between ARJI and ARJI-GARCH, most of the sample data reject ARJI significantly at the level of $10 \%$. This proves that the combination of GARCH and diffusion-jump model with changeable intensity helps to improve the model's goodness of fit;
(2) in all models, the Log-Likelihood value of TSDARJI-GARCH is the largest, and its AIC value is the smallest. After using LR testing method to choose among the TSDARJI-GARCH, ARJI-GARCH and ARJI, we also find almost all the sample stocks data reject ARJI-GARCH and ARJI significantly at the level of $5-10 \%$. In this sense, individual jump intensity is not only affected by the internal idiosyncratic factors, but also adjusts with the change of external state variables;

(3) When we estimate TSD-ARJI-GARCH model by the data from cross-holding companies, we choose the fluctuation of market index (capturing the systematic effect) and the fluctuation of share-holding company (capturing the contagious effect) as external state variable respectively. From the estimation results, we find, for "share-held company", the model with the contagious effect boasts larger log-likelihood value and smaller AIC value; but for "share-holding company", the model with the systematic effect boasts larger log-likelihood value and smaller AIC value. This suggests that the contagious effect between cross-holding companies may be single-directional contagion, i.e. the larger fluctuation of share-holding company induce an obvious response from share-held company, but the opposite directional contagious effect is insignificant.

\section{Conclusions}

We develop TSD-ARJI-GARCH model to capture the jump behavior of the return of individual stock and pay special attention to the contagious effects of large fluctuations between cross-shareholding companies. From our research, we find the jump intensity of individual stock is driven by idiosyncratic factors and thus show the features of time variation, clustering and cross-period dependence on one hand, and it also adjusts its own change process constantly under the impact of external state variables on the other hand. In addition, the effect of external state variable on the jump intensity of individual stock is dependent on the particular threshold value, so it is also called the threshold-based effect in this paper. Comparing with the existing models, TSD-ARJIGARCH model boasts better goodness of fit and explanatory ability. It comprehensively considers the timely effect of external and internal factors on individual jumps. Our research can help investors and managers to more comprehensively study the jump features in the return of individual assets in China's stock market.

\section{Acknowledgment}

This research project is funded by National Natural Science Foundation of China (Approval Number: 71201068)

\section{References}

[1] Bekaert G, Gray S. F. Target Zones and Exchange Rates: An Empirical Investigation. Journal of International Economics, 1998, 45(1):1-35.

[2] Chan W. H, Maheu J. M. Conditional Jump Dynamics in Stock Market Returns. Journal of Business \& Economic Statistics, 2002, 20(3):377389. 
[3] Daal E, Naka A, Yu J. S. Volatility Clustering, Leverage Effects and Jump dynamics in the US and Emerging Asian Equity Markets. Journal of Banking \& Finance, 2007, 31(9):2751-2769.

[4] Das S. R. The Surprise Element: Jumps in Interest Rate. Journal of Econometrics, 2002, 106(1):27-65.

[5] Huang R.. Jump Behavior Based Stock Asset Return and Default Risk of the Companies Listed in China. HuaZhong University of Science and Technology, 2011, WuHan, China

[6] Johannes M, Kumar R, Polson N. G. State Dependent Jump Models: How Do U.S. Equity Indices Jump?, 1999, Working Paper, Graduate School of Business, University of Chicago.

[7] Klebaner F. C. Introduction to Stochastic Calculus with Applications (Second Edition). Published by Imperial College Press, London, 2005, 234-236, 267-285
[8] Maheu J. M, McCurdy T. H. News Arrival, Jump Dynamics and Volatility Components for Individual Stock Returns. Journal of Finance, 2004, 59(2):755-793.

[9] Merton R. C. Option Pricing When Underlying Stock Return Are Discontinuous. Journal of Financial Economics, 1976, 3(1-2):125-144.

[10] Neely C. J. Target Zones and Conditional Volatility: The Role of Realignments. Journal of Empirical Finance, 1999, 6(2):177-192.

[11] Press S. J. A Compound Events Model for Security Prices. Journal of Business, 1967, 40(3):317-335.

[12] Tang Q.M., Huang R. Jump-Diffusion Model Based on Default Risk Measurement and Analysis for Listed Company in China. The Journal of Quantitative \& Technical Economics, 2010, 27(10):101-115. 